RESEARCHARTICLE

\title{
Assessment of Size, Shape, and Position of Palatal Rugae: A Preliminary Study
}

\author{
Bruno Nehme Barbo, Fabiane Azeredo, and Luciane Macedo de Menezes*
}

Department of Orthodontics, Pontifical Catholic University of Rio Grande do Sul, Porto Alegre, Rio Grande do Sul, Brazil

\begin{abstract}
The aims of this study were to review the literature on palatal rugae and their classification, and assess the pattern, shape, and average size in the medial-lateral direction of the first three anterior rugae of each side. In addition, we studied the factors influencing its size, with subsequent comparison of the results between gender, using digital models. This was a quantitative and qualitative study where 33 digitalized models of growing children (19 boys and 14 girls) from a previous research were evaluated. The palatal rugae were classified according to their shape and measurements were performed from the most medial point to the most lateral point of each of the first three anterior rugae on both sides using the OrthoAnalyser software (3 Shape). The most common palatal ruga shape was sinuous, followed by angle, curve, and straight, which together added up to over $90 \%$ (182 of 197) of the rugae shapes. As for the position, the most frequent in the first ruga (R1) was angle; whereas the sinuous shape predominated in the second (R2) and third (R3) rugae. The factors that influenced the sizes of the rugae include shape, number, and gender of the patients. The side of the rugae did not exert significant influence on its size. Palatal rugae did not exhibit a size pattern according to their shape and number. It is necessary to assess each patient individually in order to identify the variation regarding the shape and size of a particular palatal ruga.
\end{abstract}

Open Access

Citation: Barbo, BN, Azeredo F, Menezes LM. Assessment of Size, Shape, and Position of Palatal Rugae: A Preliminary Study. Oral Health and Dental Studies. 2018; 1(1):3.

Received: Mar 21, 2018

Accepted: May 18, 2018

Published: May 27, 2018

Copyright: @ 2018 Menezes LM et al. This is an open access article distributed under the terms of the Creative Commons Attribution License, which permits unrestricted use distribution, and reproduction in any medium, provided the original author and source are credited.

Corresponding author: Luciane Macedo de Menezes, Pontifical Catholic University of Rio Grande do Sul, Brazil.

E-mail: luciane@portoweb.com.br

\section{Keywords}

Orthodontics, forensic dentistry, palate, three-dimensional imaging, dental models

\section{Introduction}

The use of palatal rugae in dentistry is an alternative method for human identification, especially in cases of traffic accidents, acts of terrorism, and mass disasters, when it is difficult to identify individuals through fingerprints or dental arches. ${ }^{1,2}$ In orthodontics, rugae can be an auxiliary tool in diagnosis according to the literature. In some cases, it is possible to assess orthodontic movements using the palatal rugae as stable references. ${ }^{3,4}$

Palatal rugae are elevations or asymmetric ridges, ${ }^{5}$ located in the anterior portion of the palatal mucosa, bilaterally to the median palatal raphe, never crossing the midline, and posterior to the incisive papilla, also called palatal transverse folds. ${ }^{6}$ In the human embryo, the palatal rugae occupy most of the length of the palatal shelves at the time of their elevation. ${ }^{7}$ They are formed in the third month of intrauterine life and, after this period, their characteristics do not change, except in size due to their normal growth. ${ }^{7-10}$ At the end of intrauterine life, the pattern of the rugae becomes more regular, with the anterior rugae considerably more pronounced and compressed. ${ }^{6}$ At birth, the palatal rugae are complete, with the typical shape, length, width, prominence, position, and orientation creating a unique pattern for each person. ${ }^{1,11}$

Rugae feature a wide range of individual characteristics and remain stable over long periods of life. ${ }^{6,12}$ The functions of the palatal rugae include facilitating food transportation, preventing 
loss of food through the mouth, participating in the chewing process, contributing to the perception of taste, perceiving food texture, and aiding in the position of the tongue. Further, rugae play a role in phonation, since they disperse sound waves in different directions, thus giving peculiar sounding and timbre to the voice. They protect the palatal mucosa from trauma caused by hard or fibrous food and retain the saliva ${ }^{13,14}$ Rugae are protected from traumas due to their position within the oral cavity. They have heat insulation by the tongue and intraoral soft tissue. ${ }^{3,7}$ However, some events may contribute to change their pattern, such as fingersucking habit when occurring for a long period in childhood and during orthodontic treatments. ${ }^{12,15,16}$ Occasionally, there may be a change in the position of the rugae after dental extractions. ${ }^{2,8}$ There are several classifications of palatal rugae; however, the current classification systems and quantification measurements are based on two-dimensional approaches. ${ }^{10,17,18}$ Some of the Classification systems are presented in Figure 1.

Since the last century, the palatal rugae have been used as references to compare dental movements occurring before and after orthodontic treatments; however, this procedure is controversial. ${ }^{2,16,19}$ Some authors ${ }^{2,11}$ consider that the use of the palatal rugae for determining the direction and/or magnitude of the dental movement is limited. This limitation seems to be associated with the tooth position in relation to the rugae position: the closer the rugae points are located to the displaced teeth, the more the relative position of the rugae point will be affected. ${ }^{19}$ On the other hand, some authors ${ }^{3,20,21}$ report that the rugae feature a long-term stability suitable for assessment in orthodontics.

\begin{tabular}{|c|c|c|c|c|}
\hline Author/ Year & Methods Details & \multicolumn{3}{|c|}{ Classification } \\
\hline \multirow[t]{2}{*}{ Trobo (1932) } & \multirow{2}{*}{$\begin{array}{l}\text { Divided the rugae into two groups: } \\
\text { - Simple: classified from A to F. } \\
\text { - Composed: result from two or more simple rugae unions (classified } \\
\text { with the letter X). } \\
\text { Rugogram: Starts from right to left, beginning from the main rugae } \\
\text { (the closest to the median raphe), represented by a capital letter. } \\
\text { The following rugae are represented by small letters. } \\
\text { The left side of the palate is described using the same criterion. }\end{array}$} & Main Rugae & $\begin{array}{l}\text { Accessory } \\
\text { Rugae }\end{array}$ & Rugae Type \\
\hline & & $\begin{array}{l}\mathrm{A} \\
\mathrm{B} \\
\mathrm{C} \\
\mathrm{D} \\
\mathrm{E} \\
\mathrm{F} \\
\mathrm{X}\end{array}$ & $\begin{array}{l}1 \\
2 \\
3 \\
4 \\
5 \\
6 \\
7 \\
\end{array}$ & $\begin{array}{c}\text { Point } \\
\text { Straight } \\
\text { Curve } \\
\text { Angle } \\
\text { Sinuous } \\
\text { Circle } \\
\text { Composed }\end{array}$ \\
\hline $\begin{array}{l}\text { Martins dos } \\
\text { Santos (1946) }\end{array}$ & $\begin{array}{l}\text { Regarding the shape: according to the chart. } \\
\text { Regarding the position: } \\
\text { - One initial ruga: the most anterior ruga on the right side, } \\
\text { represented by a capital letter; } \\
\text { - Several Complementary: the other rugae on the right side, } \\
\text { represented by numbers; } \\
\text { - One Subinicial ruga: the most anterior ruga on the left side, } \\
\text { represented by a capital letter; } \\
\text { - Several subcomplementary rugae: the other rugae on the left side, } \\
\text { represented by numbers. }\end{array}$ & $\begin{array}{l}\text { P } \\
R \\
C \\
\text { A } \\
\text { C } \\
\text { S } \\
\text { B } \\
\text { T } \\
\text { I } \\
\text { An }\end{array}$ & $\begin{array}{l}0 \\
1 \\
2 \\
3 \\
4 \\
5 \\
6 \\
7 \\
8 \\
9 \\
\end{array}$ & $\begin{array}{l}\text { Point } \\
\text { Straight } \\
\text { Curve } \\
\text { Angle } \\
\text { Circle } \\
\text { Sinuous } \\
\text { Bifurcated } \\
\text { Trifurcated } \\
\text { Interrupt } \\
\text { Anomaly } \\
\end{array}$ \\
\hline \multirow[t]{2}{*}{ Basauri (1961) } & \multirow[t]{2}{*}{$\begin{array}{l}\text { Divided the rugae into two groups: } \\
\text { - Simple rugae: classified from A to F; } \\
\text { - Composed rugae: represented by the letter X, union from two or } \\
\text { more simple rugae. } \\
\text { Rugogram:- Starts from the right to the left beginning in the main } \\
\text { ruga (the most anterior), represented by a capital letter, and the } \\
\text { following rugae are represented by small letters. } \\
\text { - The left side of the palate is described using the same criterion. }\end{array}$} & $\begin{array}{l}\text { A } \\
B \\
C \\
D \\
E \\
F \\
X\end{array}$ & $\begin{array}{l}1 \\
2 \\
3 \\
4 \\
5 \\
6 \\
7\end{array}$ & $\begin{array}{c}\text { Point } \\
\text { Straight } \\
\text { Curve } \\
\text { Angle } \\
\text { Sinuous } \\
\text { Circle } \\
\text { Composed } \\
\end{array}$ \\
\hline & & & & \\
\hline \multirow{3}{*}{$\begin{array}{c}\text { Thomas e } \\
\text { Kotze (1983) }\end{array}$} & \multirow{3}{*}{$\begin{array}{l}\text { - Rugae: primary }(\geq 5 \mathrm{~mm}) \text {; secondary }(3-5 \mathrm{~mm}) \text {; fragmentary } \\
(2-3 \mathrm{~mm}) \text {. } \\
\text { - Shapes of primary rugae: annular, papillary, cross-link, branches, } \\
\text { unification and break. } \\
\text { - Unification: Less than } 1 \mathrm{~mm} \text { from the origin to the diverge laterally. } \\
\text { primary: two primary rugae are joint at their origin, and then } \\
\text { diverge laterally. } \\
\text { non-primary: Unification occurring between a primary ruga and } \\
\text { another ruga that is between } 1 \mathrm{~mm} \text { and } 5 \mathrm{~mm} \text { in length. } \\
\text {-Branche: A ruga which is } 1 \mathrm{~mm} \text { or more in length and leaves the } \\
\text { parent ruga } 1 \mathrm{~mm} \text { or more from its origin in a lateral direction. }\end{array}$} & & & \\
\hline & & \multicolumn{3}{|c|}{$\begin{array}{l}\text { Diference in Rugae Unification and Branche: } \\
1 \text { - primary } \\
\text { 2-non-primary } \\
\text { 3- Branche }\end{array}$} \\
\hline & & & & \\
\hline
\end{tabular}

Figure 1. Summary of the classifications of palatal rugae

Many studies have evaluated the results of orthodontic treatments using plaster models. ${ }^{4,16,19,22}$ Conventional stone models do not allow the superposition of pre- and posttreatment models and so, do not provide a precise assessment of the modifications that occur individually in the rugae (in their position with respect to transverse, antero posterior, and 
vertical directions), and linear measurements are not sufficient for comparing different models using the palatal rugae. Currently, this can be done with the digital models and for this reason they are considered as effective tools in evaluating the different palatal ruga patterns. ${ }^{[23,24]}$ Digital models began finding application toward the end of $1980 \mathrm{~s}^{25,26}$ At that time, plaster models, or dental impression were used for scanning the material that would provide the images and the software so that the orthodontist could view and manipulate the digital models. Nowadays, it is also possible to perform the intraoral scanning, without the necessity of performing the whole process described above..$^{27-29}$

Digital models require less rigorous archiving and massive physics storage space. Moreover, plaster models are not practical in the long term because of breakage and degradation issues associated with them. ${ }^{30,31}$ There have been a lot of studies comparing digital models and plaster models in relation to diagnostic accuracy and it was reported that information obtained from digital models is interchangeable with direct caliper measurements made on conventional plaster models, showing near-excellent agreement between conventional and digital models. ${ }^{22,32-39}$

The purpose of this study was to review the literature on palatal rugae and its classification systems, and to assess, using digital models, the pattern, shape, and average size of the first three anterior rugae of each side, comparing the results between gender.

\section{Material and Methods}

\section{Study Design and Sample Selection}

The sample was selected using a non-probabilistic convenience strategy from a previous research. After the approval of this research by the Ethics Committee of the Pontifical Catholic University of Rio Grande do Sul (PUCRS)( CAAE: 15960713.1.0000.5336), plaster models of 33 growing patients (19 boys and 14 girls) were randomly selected from an expansion research sample of the Orthodontic Clinic of the PUCRS School of Dentistry. The average age of the individuals in the sample ranged from 10 to 14 years.

The inclusion criterion was pre-existent plaster models from PUCRS database with good visualization of the region of the palatal rugae and no history of previous orthodontic treatment.

\section{Plaster Models Scanning}

The plaster models were scanned using the XCAD Scanner (São Paulo, State of São Paulo, Brazil) and Ortho Analyser software (Version 2012-1, 3 Shape, Copenhagen, Denmark) to analyze the images.

\section{Assessment of the Digital Models}

The study comprised qualitative and quantitative evaluations. All the assessments were carried out by manipulating the digital models spatially, thus allowing better visualization of the area using the three-dimensional rotation tool. The operator could browse and view the models from any direction and any angle and magnify the images when necessary.

The qualitative or categorical data analyzed included the classification of the shape of the rugae, performed adapting the method proposed by Basauri, described by Caldas et al. ${ }^{9}$, assessing the first three rugae on each side. The quantitative data was composed of linear measurements from the most medial point to the most lateral point of each of the first three anterior rugae on each side (Figure 2). The rugogram was carried out from the right to the left, separating the sides by the median palatal raphae and starting from the main ruga (the most anterior - the closest to the incisive papilla) named as "right first ruga" (R1R), and the two following rugae named as"right second" and "right third ruga" (R2R and R3R, respectively). Finally, the left side of the palate was assessed using the same criterion ("left first ruga" L1R, and "left second ruga" and "third ruga"- L2R and L3R, respectively). Each ruga was classified according to its shape, as illustrated in Figure 3. 


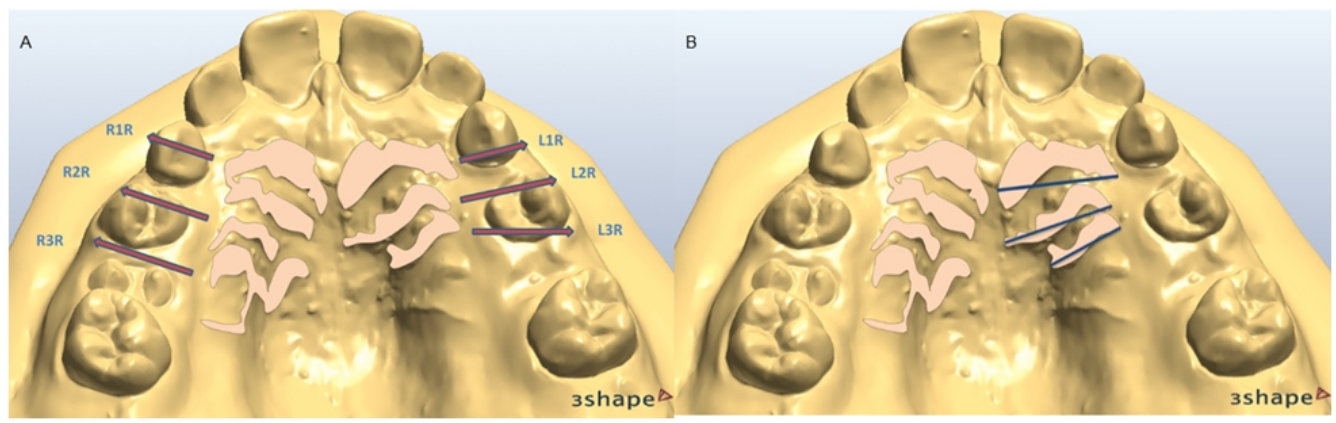

Figure 2. (A) Sequence and position of the first three rugae of the right and left sides. (R1R and L1R) first rugae; (R2R and L2R) second rugae; (R3R and L3R) third rugae (B) Measurement in the medial-lateral direction of the rugae of the left side

Linear measurements were carried out from the most medial point to the most lateral point of each of the first three anterior rugae on both sides (Figure 2B) using the tool "distance with digital calliper" of the OrthoAnalyser software (version 2012-1, 3Shape). Results obtained from female and male patients were compared to check for the possible differences. All the assessments and measurements were performed by the same examiner (B.B) and repeated three times at a 15-day interval.

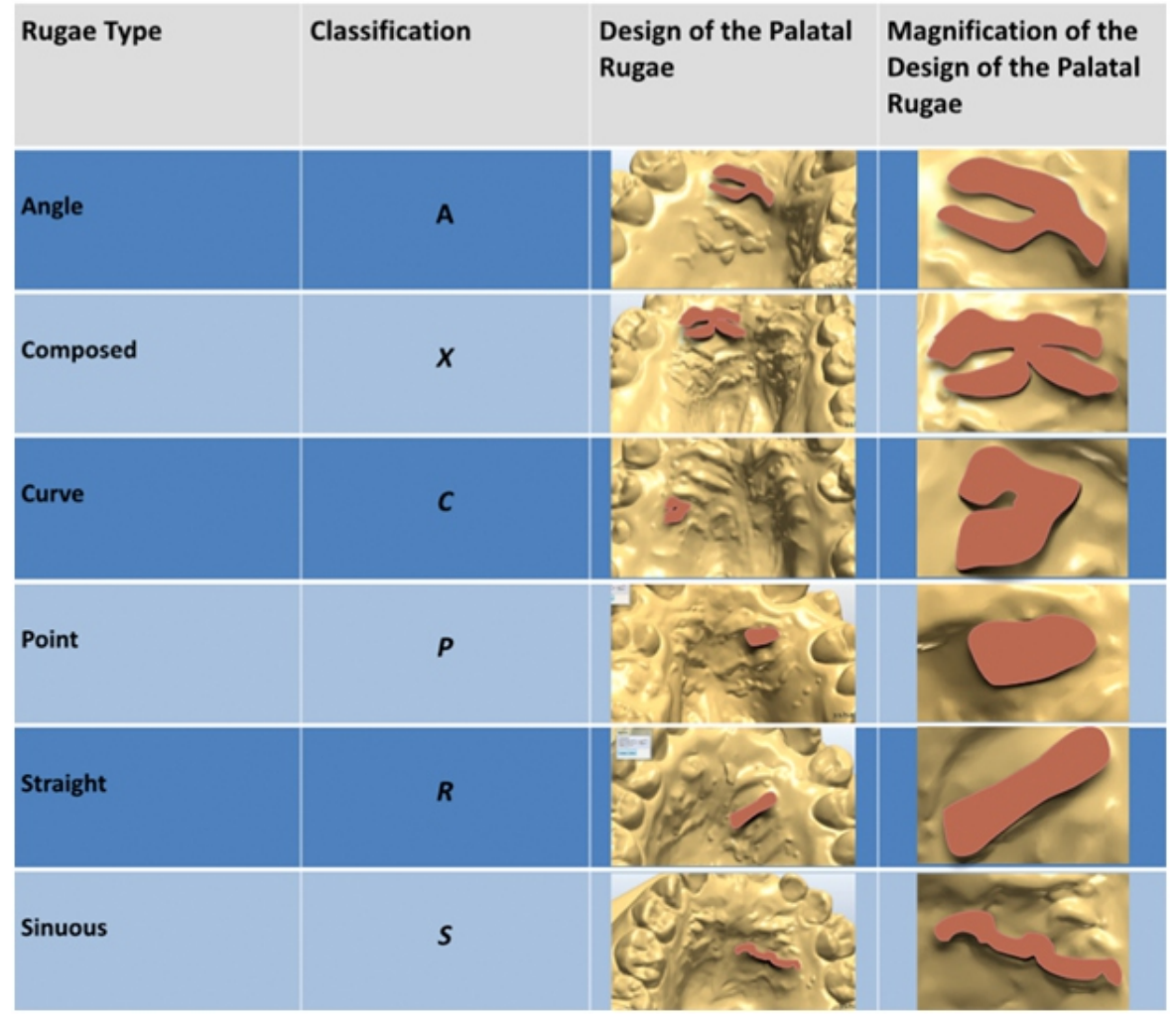

Figure 3. Rugae classification according to the shape

\section{Statistical Analysis}

The values obtained from the categorical variables were expressed as percentages. Alinear mixed model (hierarchical model) was used to assess the impact of various factors on the size of the rugae, taking into consideration the shape of the ruga observed individually and the measurements performed. Additionally, two models were developed, including effects of interaction between ruga-number and ruga-shape and between ruga-number and patients' gender. All the statistical analyses were calculated using IBM SPSS statistics (version 21.0 Chicago, USA).

\section{Results}

\section{Shape Assessment}

Intra class correlation coefficient (ICC) ranged from 0.999 to 1.000 . The most common 
shape of palatal rugae observed was sinuous (45\%), followed by angle (18\%), curve (15\%), and straight (14\%), which altogether added up to over $90 \%$ of the rugae shape.

The distribution of the rugae shape with respect to the morphology was different in rugae one, two, and three (R1, R2 and R3). The most common shape of the first rugae was angle $(39 \%)$ and the most frequent shape of the second and third rugae was sinuous $(58 \%$ and $62 \%$, respectively). Table 1.

Table 1. Distribution of rugae with respect to the shape

\begin{tabular}{|c|c|c|c|c|c|c|c|c|c|}
\hline Cla & & Sinuous & Angle & Curve & & ight & & osed & Point \\
\hline Rugae & $\mathbf{n}$ & n $\quad(\%)$ & n $\quad(\%)$ & n $\quad(\%)$ & & (\%) & n & $(\%)$ & n (\%) \\
\hline 1st & 66 & $11 \quad(17)$ & $\begin{array}{ll}26 & (39)\end{array}$ & $12(18)$ & & (11) & 9 & (14) & $\begin{array}{ll}1 & (1)\end{array}$ \\
\hline 2nd & 66 & $38 \quad(58)$ & $5 \quad(8)$ & $6(10)$ & 12 & (18) & 3 & (4) & $\begin{array}{ll}2 & (3)\end{array}$ \\
\hline 3rd & 65 & $40 \quad(62)$ & 4 & 12 (19) & 9 & (14) & - & - & - \\
\hline Total & 197 & $\begin{array}{ll}89 & (45)\end{array}$ & $35 \quad(18)$ & 30 (15) & 28 & (14) & 12 & (6) & $3 \quad(2)$ \\
\hline
\end{tabular}

\section{Factors Influencing the Size of the Rugae}

The factors that influenced the size of the palatal rugae, in order of magnitude were: shape of the ruga $(P<0.001)$, number of the ruga $(P<0.001)$, and patient's gender $(P=0.009)$. The side of the ruga did not influence significantly its size $(P=0.48)$; therefore, both sides were assessed as one group (Figure 4).

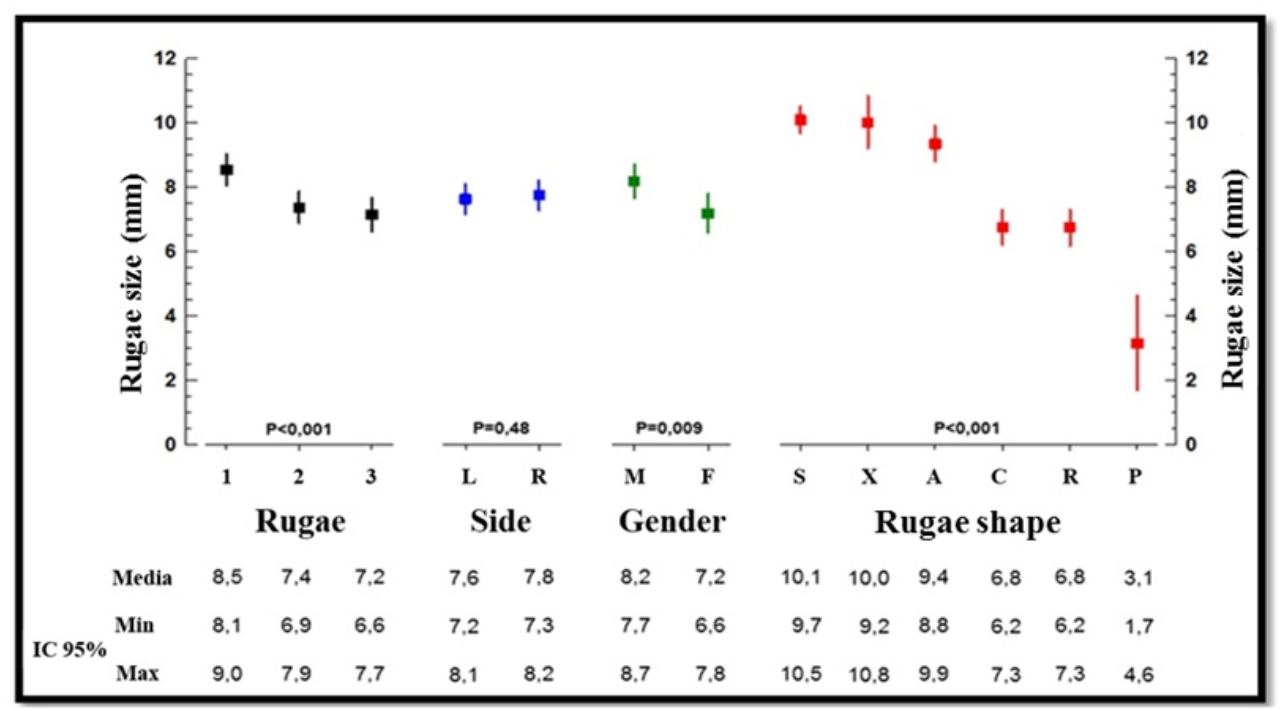

Figure 4. Influencing factors with respect to the size of the rugae

Three interactions were tested in the model. The shape of the rugae (the variable that revealed the greatest influence on the size) showed interaction with the number of the rugae $(P<0.001)$; however, no inter action was observed with the patient's gender $(P=0.089$; Figure $5)$. Additionally, it was observed that the patient's gender was correlated with the position of the ruga $(P=0.012)$, and the rugae were larger in male compared to female patients. 


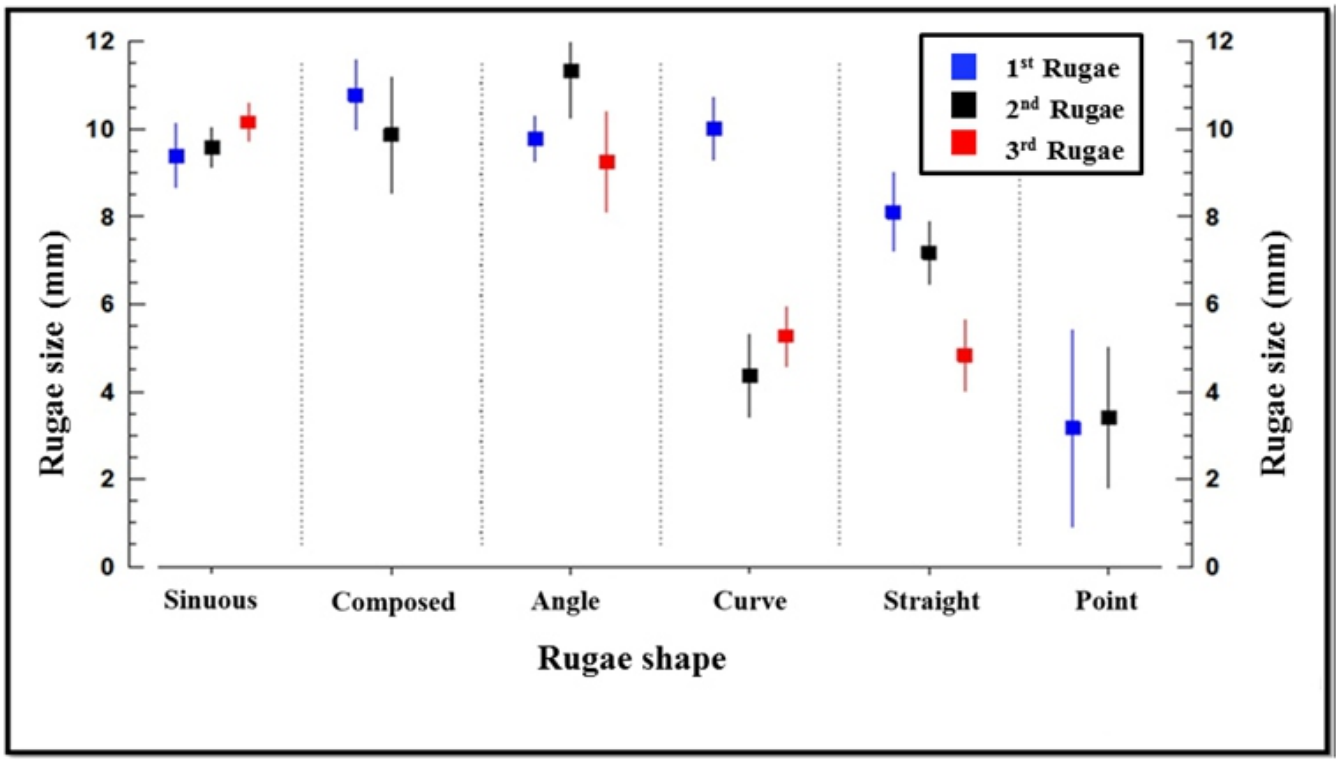

Figure 5. Interaction between the form and the position of the rugae

\section{Discussion}

Palatal rugae are unique and different in each person and, for this reason, they are used for human identification. ${ }^{1,2}$ The present study sought to assess the palatal rugae separately (R1, $\mathrm{R} 2$, and R3), observing the relationship between shape, size, and patients' gender. The first three rugae of each side were assessed, since the studies addressing the use of rugae in orthodontics used the medial points and/or the most lateral points of the first anterior three rugae and/or the palatal vault region to assess treatments or individuals' growth., ${ }^{3,20}$

\section{Comparison to Other Studies with respect to the Shape of the Rugae}

The most common palatal ruga shape found in this study was sinuous, followed by angle, curve, and straight, which constituted over $90 \%$ of the rugae shape, as observed in previous studies. ${ }^{14,40,41}$ However, the second most prevalent shape found in previous studies was curve, followed by straight. Jibi et al. ${ }^{42}$ assessed children (7-9 years) of two communities from Davanger City, India, and obtained the same result, but without using the angle shape in the classification. In a study conducted by Kallianpur et al, ${ }^{43}$ who, among other aspects, observed the shape of the rugae in Indian and Nepalese descendants, found greater prevalence of the sinuous shape in the two groups, followed by curve in the Indian and straight in the Nepalese. Byatnal et al. ${ }^{44}$ demonstrated the predominant rugae patterns and variation among different linguistic populations of five different states of India. They found that the sinuous pattern of palatal rugae was the most predominant pattern in all the study groups, which was followed by straight and curved pattern in most of the groups. Indira, Grupta, and David ${ }^{45}$ determined the pattern of rugae in human identification through the similarity in the pattern of rugae in an Indian population, from members of the same families, and between dizygotic twins. They observed greater prevalence of the curved rugae, followed by sinuous and straight. Oral, Buy uk and Simsek $^{46}$ evaluated the palatal rugae pattern in 105 individuals aged 10 to 22 years. The subjects were grouped as Class I (35, 23 females, 12 males), Class II (35, 18 females, 17 males), and Class III (35, 14 females and 21 males) according to the ANB angle measured on lateral cephalometric radiographs in order to perform the skeletal classification of the study participants (Class I: ANB angle $0^{\circ}$ to $4^{\circ}$; Class II: ANB angle $>4^{\circ}$; Class III: ANB angle < $0^{\circ}$ ). They observed that wavy and curved types were the most common types of rugae pattern in all the groups.

Each of the first three anterior rugae on both sides was assessed separately. Since there was no statistical difference between the sides ( $L$ and $R$ ), they were grouped together for evaluation purposes. Thus, in the first ruga, the most common shape was angle, followed by curve, sinuous, and straight. In the second ruga, the most prevalent shape was sinuous, followed by straight, angle, and curve, and there was a predominance of the sinuous shape in the third ruga, followed by curve, straight, and angle (Table 1). According to Santos and Caldas, ${ }^{47}$ who studied the rugae of 50 patients at the School of Dental Medicine of the University of Porto, the most prevalent shapes were straight in the first ruga and sinuous in the 
third ruga. The second ruga, however, was not assessed.

\section{Rugae Size Comparison and the Influencing Factors}

Regarding the size of the rugae assessed by digital models, some variations were observed in the present study. The length of the rugae was determined, and it was observed that sinuous, composition, and angle of the shapes of rugae were bigger, while the point shape was the smaller (Figure 4). Similar results were obtained by Venegas et al. ${ }^{40}$. They used calcorrugos copy in plaster models with Trobo's classification in a sample of 120 adult patients from the University of Talca and evaluated the shape and the biometric characteristic of palatal rugae assessing their prevalence. The comparison of the sizes of the rugae (first, second, and third) showed a significant difference between the values. The first ruga was bigger than the others, and the second and third rugae were of similar sizes.

When the size of the rugae was assessed considering the patient's gender (Figure 4), it was observed that these structures were bigger in males $(P=0.009)$; however, their magnitude was different when compared among the first three anterior rugae. This finding is contrary to what has been reported in other studies reporting no statistical difference. ${ }^{6,15,40}$

Upon comparing the sides (right vs. left) and the size of the rugae (Figure 4), it no statistical difference was observed, as described in the study conducted by Kapali et al. ${ }^{15}$

The variables that showed variation with respect to the size were the shape and number of the rugae. Therefore, in the present study an interaction between these two variables and the dependence on the size was performed (Figure 5). The shape of each ruga was separated according to the ruga number (R1, R2, and R3). In the general context, the first ruga was the biggest. When the shapes of the rugae were assessed separately, they showed variations in the size, depending on whether they were in R1, R2, or R3. It was concluded that each shape of ruga was greater in a particular ruga ( $R 1, \mathrm{R} 2$, and $\mathrm{R} 3)$.

Greater size variation was found in the curve, straight, and point shape. The curve rugae had an average diameter of $10 \mathrm{~mm}$ in R1, and averages of 4.4 and $5.3 \mathrm{~mm}$, respectively, in R2 and R3. On the other hand, the straight ruga exhibited similar size in the first two rugae ( 8.1 and 7.2 $\mathrm{mm}$ ) and was smaller in the third ruga, with an average size of $4.8 \mathrm{~mm}$. The point shape rugae exhibited significant variation in size in the first two rugae, despite the similar average of 3.2 and $3.4 \mathrm{~mm}$, respectively. Further studies are required to determine the size of the rugae with respect to their shape.

Palatal rugae were considered as stable references in orthodontics. However, to be used as such, it is necessary to acquire greater knowledge of their shape, size and length, assessing them to verify whether they remain stable during the treatment. ${ }^{2,3,11,16,20,21,24}$ There was a limitation when the sizes of the rugae were compared using data from the literature, as most of the studies have assessed the dimensions of the rugae using the classification proposed by Thomas and Kotze. ${ }^{48}$ This classification separates the rugae into primary ruga $(\geq 5 \mathrm{~mm})$, secondary ruga $(3-5 \mathrm{~mm})$, and fragmented ruga $(2-3 \mathrm{~mm})$, without specifying the average of the total size of the rugae.

Several factors such as shape, position, gender, and classification are considered when palatal rugae are studied. They exhibit variations in shape and their measures may be smaller than $2 \mathrm{~mm}$ or greater than $10 \mathrm{~mm}$, and they may be influenced by gender, number of the ruga, and the classification used. The difficulty in comparing the studies is a result of the numerous existing classifications and the lack of standardization.

\section{Conclusion}

The findings of this preliminary study indicate that the three palatal rugae assessed did not exhibit a size pattern with respect to shape and number. It is necessary to assess each patient individually, in order to identify the variation with respect to the form and size of a particular palatal ruga. Future studies, with larger sample size, should be carried out to allow more conclusive results.

\section{References}

1. Patil MS, Patil SB, Acharya AB. Palatine rugae and their significance in clinical dentistry: a review of the literature. JAm Dent Assoc. 2008;139(11):1471-1478. 
2. Peavy DC, Kendrick GS. The effects of tooth movement on the palatine rugae. $J$ Prosthet Dent. 1967;18(6):536-542.

3. Jang I, Tanaka M, Koga Y, et al. A Novel Method for the Assessment of Three-Dimensional Tooth Movement during Orthodontic Treatment. Angle Orthod. 2009;79(3):447-453.

4. Bell A, Ayoub AF, Siebert P. Assessment of the accuracy of a three-dimensional imaging system for archiving dental study models. J Orthod. 2003;30(3):219-223.

5. Simmons JD, Moore RN, Erickson LC. A Longitudinal Study of Anteroposterior Growth Changes in the Palatine Rugae. J Dent Res. 1987;66(9):1512-1515.

6. Lysell L. Plicae palatinae trasversae and papilla incisiva in man. A morphologic and genetic study. Acta Odontol Scand. 1955;13(18): 135-137.

7. Hauser G, Daponte A, Roberts M. Palatal rugae. J Anat. 1989;165:237-249.

8. Almeida M, Phillips C, Kula K, Tulloch C. Stability of the palatal rugae as landmarks for analysis of dental casts. Angle Orthod. 1995;65(1):43-48.

9. Caldas I, Magalhães T, Afonso A. Establishing identity using cheiloscopy and palatoscopy. Forensic Sci Int. 2007;165(1):1-9.

10. De Angelis D, Riboli F, Gibelli D, Cappella A, Cattaneo C. Palatal rugae as an individualising marker: Reliability for forensic odontology and personal identification. Sci Justice. 2011;52(3):181-184.

11. Kim H, Moon S, Lee S, Park Y. Three-dimensional biometric study of palatine rugae in children with a mixed-model analysis: A 9-year longitudinal study. Am J Orthod Dentofac Orthop. 2012; 141(5):590-597.

12. English W, Robison S, Summitt J, et al. Individuality of Human Palatal Rugae. J Forensic Sci. 1988;33(3):718-726.

13. Buchtová M, Tichý F, Putnová I, Míšek I. The development of palatal rugae in the European pine vole, Microtus subterraneus (Arvicolidae, Rodentia). Folia Zool. 2003;52(2):127-136.

14. Thomas CJ, Kotze TJ, Van der Merwe CA. An improved statistical method for the racial classification of man by means of palatal rugae. Arch Oral Biol. 1987;32(4):315-317.

15. Kapali S, Townsend G, Richards L, Parish T. Palatal rugae patterns in Australian Aborigines and Caucasians. AustDent J. 1997;42(2):129-133.

16. Mustafa AG, Allouh MZ, Alshehab RM. Morphological changes in palatal rugae patterns following orthodontic treatment. J Forensic Leg Med. 2015;31:19-22.

17. DawasazAA, Dinkar AD. Rugoscopy: Predominant Pattern, Uniqueness, and Stability Assessment in the Indian Goan Population. J Forensic Sci. 2013;58(6):1621-1627.

18. Herrera LM, Strapasson RAP, Mazzilli LEN, Melani RFH. Differentiation between palatal rugae patterns of twins by means of the Briñon method and an improved technique. Braz Oral Res. 2017;31:1-8.

19. Van der Linden FPGM. Changes in the position of posterior teeth in relation to ruga points. Am J Orthod. 1978;74(2):142-161.

20. Chen G, Chen S, Zhang X, et al. Stable region for maxillary dental cast superimposition in adults, studied with the aid of stable miniscrews. Orthod Craniofac Res. 2011;14(2):70-79.

21. Cha BK, Lee JY, Jost-Brinkmann P-G, Yoshida N. Analysis of tooth movement in extraction cases using three-dimensional reverse engineering technology. Eur J Orthod. 2007;29(4):325-331.

22. Whetten JL, Williamson PC, Heo G, Varnhagen C, Major PW. Variations in orthodontic treatment planning decisions of Class II patients between virtual 3-dimensional models and traditional plaster study models. Am J Orthod Dentofac Orthop. 2006;130(4):485-491.

23. Taneva E, Johnson A, Viana G, Evans C. 3D evaluation of palatal rugae for human identification using digital study models. J Forensic Dent Sci. 2015;7(3):244.

24. Gibelli D, De Angelis D, Pucciarelli V, et al. Application of 3D models of palatal rugae to personal identification: hints at identification from 3D-3D superimposition techniques. Int $\mathrm{J}$ Legal Med. 2017:1-5.

25. Joffe L. Current Products and Practices OrthoCADTM: digital models for a digital era. $J$ Orthod. 2004;31(4):344-347. 
26. Martin CB, Chalmers E V., Mclntyre GT, Cochrane H, Mossey P a. Orthodontic scanners: what's available? J Orthod. 2015;42(2):136-143.

27. Flügge T V., Schlager S, Nelson K, Nahles S, Metzger MC. Precision of intraoral digital dental impressions with iTero and extraoral digitization with the iTero and a model scanner. Am J Orthod Dentofac Orthop. 2013;144(3):471-478.

28. Akyalcin S, Dyer DJ, English JD, Sar C. Comparison of 3-dimensional dental models from different sources: Diagnostic accuracy and surface registration analysis. Am J Orthod Dentofac Orthop. 2013;144(6):831-837.

29. Creed B, Kau CH, English JD, Xia JJ, Lee RP. A Comparison of the Accuracy of Linear Measurements Obtained from Cone Beam Computerized Tomography Images and Digital Models. Semin Orthod. 2011;17(1):49-56.

30. Akyalcin S. Are Digital Models Replacing Plaster Casts? Dentistry. 2011;1(2):1-2.

31. Westerlund A, Tancredi W, Ransjö M, et al. Digital casts in orthodontics: A comparison of 4 software systems. Am J Orthod Dentofac Orthop. 2015;147(4):509-516.

32. Horton HMI, Miller JR, Gaillard PR, Larson BE. Technique Comparison for Efficient Orthodontic Tooth Measurements Using Digital Models. Angle Orthod. 2010;80(2):254-261.

33. Lippold C, Kirschneck C, Schreiber K, et al. Methodological accuracy of digital and manual model analysis in orthodontics -A retrospective clinical study. Comput Biol Med. 2015;62:103-109.

34. Dragstrem K, Galang-Boquiren MTS, Obrez A, et al. Accuracy of digital American Board of Orthodontics Discrepancy Index measurements. Am J Orthod Dentofac Orthop. 2015;148(1):60-66.

35. Fabels LNJ, Nijkamp PG. Interexaminer and intraexaminer reliabilities of 3-dimensional orthodontic digital setups. Am J Orthod Dentofac Orthop. 2014;146(6):806-811.

36. Watanabe-Kanno GA, Abrão J, Junior HM, Sánchez-Ayala A, Lagravère MO. Determination of toothsize discrepancy and Bolton ratios using bibliocast Cécile3 digital models. Int Orthod. 2010;8 (3):215-226.

37. Leifert MF, Leifert MM, Efstratiadis SS, Cangialosi TJ. Comparison of space analysis evaluations with digital models and plaster dental casts. Am J Orthod Dentofac Orthop. 2009;136(1):16.e1-16.e4.

38. Sousa MVS, Vasconcelos EC, Janson G, Garib D, Pinzan A. Accuracy and reproducibility of 3dimensional digital model measurements. Am J Orthod Dentofac Orthop. 2012;142(2):269-273.

39. Rheude B, Sadowsky PL, Ferriera A, Jacobson A. An evaluation of the use of digital study models in orthodontic diagnosis and treatment planning. Angle Orthod. 2005;75(3):300-304.

40. Venegas V, Valenzuela J, López M, Galdames I. Palatal Rugae: Systematic Analysis of its Shape and Dimensions for Use in Human Identification. Int J Morphol. 2009;27(3):819-825.

41. Nayak $P, A$ charya AB, Padmini AT, Kaveri H. Differences in the palatal rugae shape in two populations of India. Arch Oral Biol. 2007;52(10):977-982.

42. Jibi PM, Gautam KK, Basappa N, Raju OS. Morphological Pattern of Palatal Rugae in Children of Davangere. J Forensic Sci. 2011;56(5):1192-1197.

43. Kallianpur S, Desai A, Kasetty S, Sudheendra U, Joshi P. An anthropometric analysis of facial height, arch length, and palatal rugae in the Indian and Nepalese population. J Forensic Dent Sci. 2011;3(1):33-37.

44. Guruprasad Y, Telagi N, Byatnal A, et al. Palatoscopy: An adjunct to forensic odontology: A comparative study among five different populations of India. J Nat Sci Biol Med. 2014;5(1):52-56.

45. Indira A, Gupta M, David M. Palatal rugae patterns for establishing individuality. J Forensic Dent Sci. 2012;4(1):2-5.

46. Oral E, Buyuk SK, Simsek H. Evaluation of palatal rugae pattern in different sagittal skeletal relationship adolescent subjects. Med (United States). 2017;96(14):1-4.

47. Santos C, Caldas IM. Palatal Rugae Pattern in a Portuguese Population: A Preliminary Analysis. $J$ Forensic Sci. 2012;57(3):786-788.

48. Thomas C, Kotze T. The palatal ruga pattern: a new classification. J Dent Assoc South Africa. 1983;38:153-176. 